\title{
Lasso Peptides and Murein Peptide Ligase Inhibitors as Novel Anti-Mycobacterial Agents
}

\author{
Francesca Scotti ${ }^{1,2}$, Sanjib Bhakta ${ }^{2}$, and John P. Malkinson ${ }^{1}$ \\ ${ }^{1}$ UCL School of Pharmacy, 29-39 Brunswick Square, WC1N 1AX, London, UK; \\ ${ }^{2}$ Birkbeck College, Malet Place WClE 7HX, London, UK
}

\section{Introduction}

Despite the existence of vaccinations, diagnostic tools and treatments, tuberculosis (TB) prevalence is increasing because of the increased circulation of people, the misuse of antibacterials - giving rise to growing numbers of drug resistant strains of Mycobacterium tuberculosis, low compliance with the lengthy therapy - four different drugs for six months, and deadly liaisons with other health concerns (AIDS, diabetes, cancer, etc.). There is therefore a pressing need to look for new strategies against TB, in the hope of finding new drugs with novel mechanisms of action or ways to potentiate the activity of existing drugs and to reduce treatment duration. Recently, among the class of lasso peptides, interesting stable cyclic peptides of bacterial origin were reported, including the anti-mycobacterial lariatins A and B, followed by the newly-discovered anti-TB pseudo-lasso peptide lassomycin [1-3]. Furthermore the identification in $M$. tuberculosis of an orthologue of an enzyme found in E. coli [4,5] involved in peptidoglycan recycling encouraged us to try to identify and evaluate its activity and find potential inhibitors.

\section{Results and Discussion}

The choice of potential inhibitors of Mpl was based on structural analogy with the putative natural peptide substrates identified in E.coli [4,5]. These small peptides have been synthesised via solid-phase synthesis and have been tested using M. aurum through the SpotI whole-cell high-throughput screening assay [6].
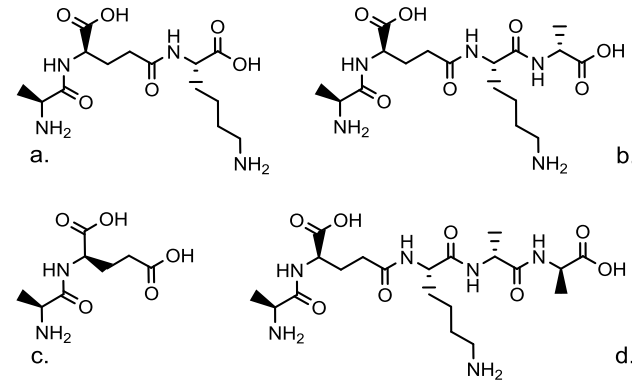

Fig. 1. First structural analogues of putative Mpl natural substrates synthesized.
The intention is to characterise $\mathrm{Mpl}$ activity in M. tuberculosis in order to confirm its substrates and evaluate the activity of analogues at the enzyme level. In order to achieve this, recombinant M. tuberculosis $\mathrm{Mpl}$ has been heterologously expressed in E. coli BL21(DE3)-pLysS competent cells and purified. Automated solid-phase peptide synthesis has been utilised to rapidly synthesise multiple short branched peptide analogues in parallel which have been tested on $M$. aurum using the SpotI high-throughput screening assay [6]. The results so far show no significant inhibiting activity.

Lariatin A, lariatin B and lassomycin as well as their linear precursors have been synthesised via solid-phase synthesis. Initial efforts adopted an onresin head-to-side chain cyclisation strategy based upon the use of the semi-permanent Dmab protecting group. Unfortunately the use of this group was associated with troublesome side-reactions, including chain termination by pyroglutamate formation (lariatins) and aspartimide formation (lassomycin), requiring modification of the strategy and use of an allyl ester.

The SpotI whole-cell high-throughput screening assay, on a valid mycobacterial surrogate [7], will be used to evaluate whether these synthetic molecules adopt their appropriate bioactive conformations and whether the linear precursor retains their anti-mycobacterial activity. 

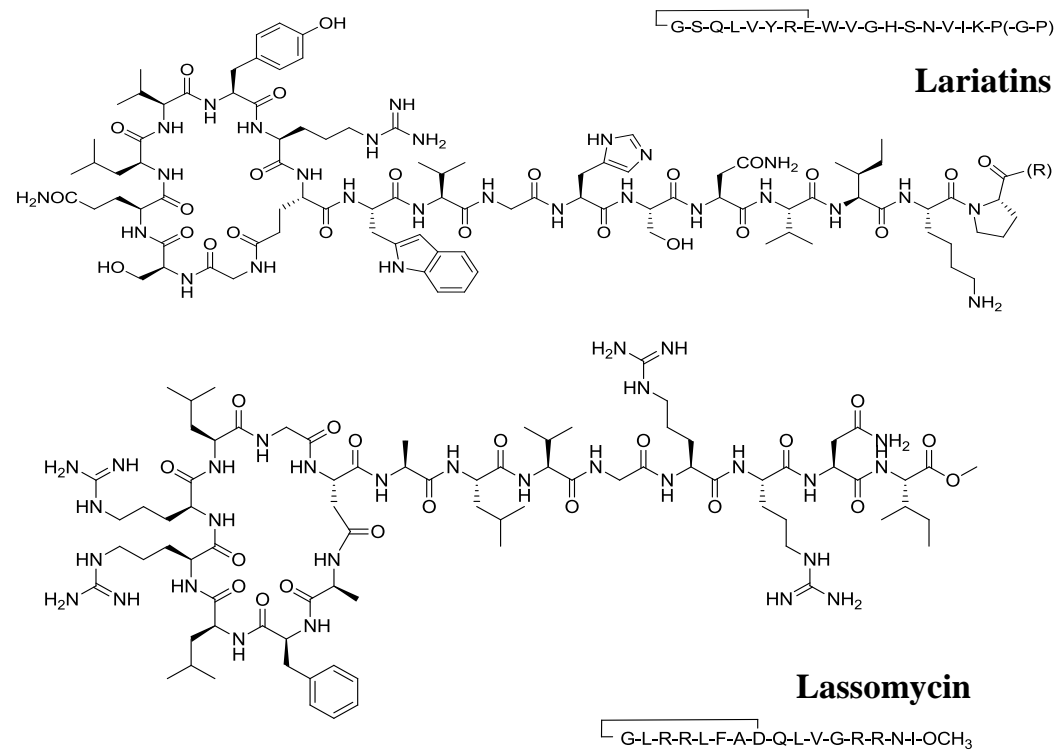

Fig. 2. Schematic representation of lariatins and lassomycin structure.

\section{Acknowledgments}

This work was supported by Bloomsbury Colleges Consortium, London, UK. F.S. is grateful to APS and UCL School of Pharmacy for providing travel funds.

\section{References}

1. Maksimov, M.O., et al. Proc. Natl. Acad. Sci. USA 109, 15223-15228 (2012), http://dx.doi.org/10.1073/pnas.1208978109

2. Iwatzuki, M., et al. J. Am. Chem. Soc. 128, $7486-7491$ (2006), http://dx.doi.org/10.1021/ja056780z

3. Gavrish, E., et al. Chem. Biol. 21, 509-518 (2014), http://dx.doi.org/10.1016/j.chembiol.2014.01.014

4. Das, D., et al. PLoS One 6, e17624 (2011), http://dx.doi.org/10.1371/journal.pone.0017624

5. Hervè, M,. et al. Biochimie 95, 1120-1126 (2013), http://dx.doi.org/10.1016/j.biochi.2012.12.011

6. Gupta, N., et al. J. Antimicrob. Chemother. 67, 1380-1391 (2012), http://dx.doi.org/10.1093/jac/dks056

7. Gupta, N., et al. J. Antimicrob. Chemother. 64, 774-781 (2009), http://dx.doi.org/10.1093/jac/dkp279 